BRADY, J. V., \& NAUTA, W. J. H. Subcortical mechanisms in emotional behavior: The duration of affective changes following septal and habenular lesions in the albino rat. Journal of Comparative \& Physiological Psychology, $1955,48,412-420$.

EPSTEIN, A. N. Reciprocal changes in feeding behavior produced by intrahypothalamic chemical injections. American Journal of Physiology, 1960, 199, 969-974.

ESTES, W. K., \& SKINNER, B. F. Some quantitative properties of anxiety. Journal of Experimental Psychology, 1941, 29, 390-400.

HAETIG, E. W., \& MASSERMAN, J. H. Hypothalamic lesions and pneumonia in cats. Joumal of Neurophysiology, 1940, 3, 293-299.

HANAI, $T$., \& DELGADO, J. Microinjections of drugs within the brain of awake monkeys. Paper presented at XXIII International Congress of Physiological Sciences, 1967.

INGRAM, W. R., BARRIS, R. W., \& RANSON, S W. Catalepsy: An experimental study. Archives of Neurology \& Psychiatry (Chicago), 1936, 35, 1175.1197.

KAWAMURA, H., \& OSHIMA, K. Effect of adrenaline on the hypothalamic activating system. Japanese Joumal of Physiology, 1962 12, 225-233.

KAWAMURA, H., NAKAMURA, Y., \& TOKIZANE, T. Effect of acute brain stem lesions on the electrical activities of the limbic system and neocortex. Japanese Joumal of Physiology, 1961, 11, 564-575.

MARGULES, D. L., \& STEIN, L. Cholinergic synapses in the ventral medial hypothaiamus for the suppression of operant behavior by punishment and satiety. Joumal of Comparative \& Physiological Psychology, 67, 1969, 327-335.

PAPEZ, J. W. A proposed mechanism of emotion. Archives of Neurology \& Psychiatry (Chicago) $1937,38,725-743$.

\title{
Daily activity schedule of captive opossums
}

ROCCO A. BOMBARDIERI, JR., Zoology Department, and JOHN I. JOHNSON, JR., Biophysics, Psychology, and Zoology Departments, Michigan State University, East Lansing, Mich. 48823

A stratified time-sampling technique was used to describe quantitatively, in terms of observed probabilities, the time of occurrence and variety of activities in captive opossums. Opossums are awake and grooming between 6:00 PM and 8:00 AM, with most types of other activities occurring between 10:00 PM and 8:00 AM. The opossums spend the rest of the day, 8:00 AM through 6:00 PM, resting or sleeping.

In general references on opossums, Didelphis marsupialis (Hartman, 1952; Keefe, 1967; Reynolds, 1953), there are few data concerning their diel activity pattems. Therefore, the quantitative data that we have obtained may prove valuable to other investigators of opossum behavior in the laboratory. They show, in a definite and discrete way, the distribution of activities in time. This study was designed to describe the time of occurrence and the varieties of activities observed in captive opossums studied over a period of 30 days.

\section{METHODS}

Six animals, two adult females, two adult males, and two juvenile females, were selected for this study. They were kept in a colony with six other animals, one adult and five juvenile females. The animals were originally obtained from commercial sources in North Carolina and Texas. The study was conducted in August 1968, in a barn on the Michigan State University farms near East Lansing, Michigan. All animals were marked for identification with Nyanzol-D dye, and the entire colony was kept in a $3.9 \times 2.8 \mathrm{~m}$ ( $\times 2.3 \mathrm{~m}$ high) hardware cloth enclosure within the barn. Within the enclosure, there were three elevated boxes that were used by the animals for rest or sleep, and tree branches that the animals used to climb from the floor to the boxes. All observations were made from outside the pen. At night a small flashlight or the barn lights were used to make the animals visible.

Observations were made using a stratified time-sampling technique in which the 24-h day was divided into six 4h "parts" (Hours 1-4, Hours 5-8, etc.). Observations were conducted on 6 days of each week, and each "part" of the day was represented by one observation in each of the 4 weeks. A random-number table was used to select the time of observation for each day during the study, always maintaining the criteria that each of the six "parts" of the day was represented once in every week, and each hour of the day was represented once in the study. The order of animals observed was also randomized.

Beginning at the designated time, each animal was observed for $5 \mathrm{~min}$, divided into 10 consecutive $30-\mathrm{sec}$ time bins. Everything the animal did in that period was recorded in a notebook, or on tape and later transcribed to a notebook. At the end of all the observation periods, various categories of behavior were defined, and the notebook was scored by noting the presence or absence of each behavior, in each time bin, for each animal. There was, therefore, a maximum score of 60 for each hour for each behavior (six animals $x 10$ bins). To check for accuracy of observation and scoring, two Os recorded independently during one session in each of the six "parts" of the day. RESULTS AND DISCUSSION

The categories of behavior that were scored are listed and defined below:

(1) Ambulation: Moving or turning on a level surface.

(2) Climbing: Moving up or down hardware cloth, branches, or around boxes.

(3) Investigation: Sniffing environment (exclusive of nosing behavior).

(4) Nosing: Placing nose near another animal.

(5) Grooming: Cleaning self with mouth, paw, face, or tongue.

(6) Consummatory: Ingestion of solid food, or water (which were available at all times).

(7) Resting: Sleep or resting (resting is distinguished from observing behavior by the general lack of body movements except for an occasional adjustment of body position which occurs even during sleep).

(8) Observing: Periods of wakefulness during which the animal is not doing anything that would place him in another category.

(9) Passive social contact: Sleeping, resting, sitting, or standing in physical contact with another animal.

(10)Active social contact: Nosing, pawing, or biting another animal. Also includes climbing on or around another animal as well as growling at another animal.

Behaviors scored, but not graphically analyzed because they occurred too rarely: (11)Aggression: Biting or growling at another animal.

(12)Submission: Retreating after an aggressive display of another animal.

(13)Y awning: Self-descriptive.

The scores of the principal $O$ and the second Os correlated highly $(r=.95)$.

Figure 1 shows graphs which plot the time of day against the total number of bins in which a particular behavior was observed for the six animals; each point represents the sum of $2 \mathrm{~h}$ of observation. Graphs A-E demonstrate clear diel patterns of activity. For each of these behaviors-ambulation, climbing, investigation, nosing, and active social-there seems to be an approximately 10-h activity period beginning about 10:00 p.m. (Hour 22, approximately $1 \mathrm{~h}$ after sunset), and lasting until approximately 8:00 a.m. (approximately $1 \mathrm{~h}$ after sunrise). Consummatory behavior shows an activity period that is slightly later, and also a burst of activity in the afternoon, but the frequency of this category is too small to warrant conclusions. Graphs $G$ and $\mathrm{H}$, observing and grooming, show a much 

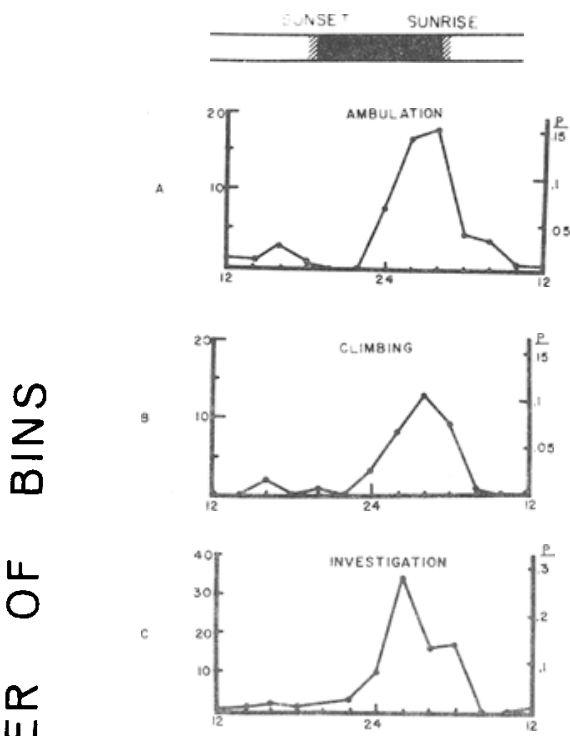

$\sum_{\sum}^{\infty}$
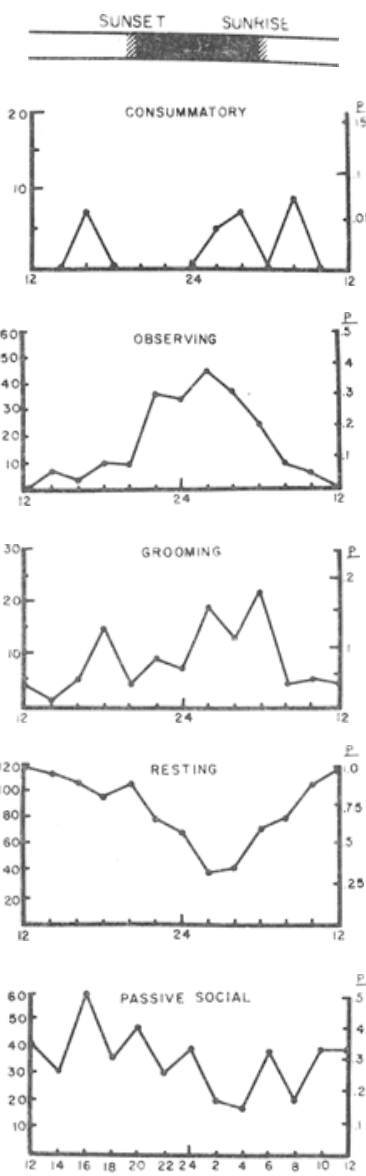

PM

AM

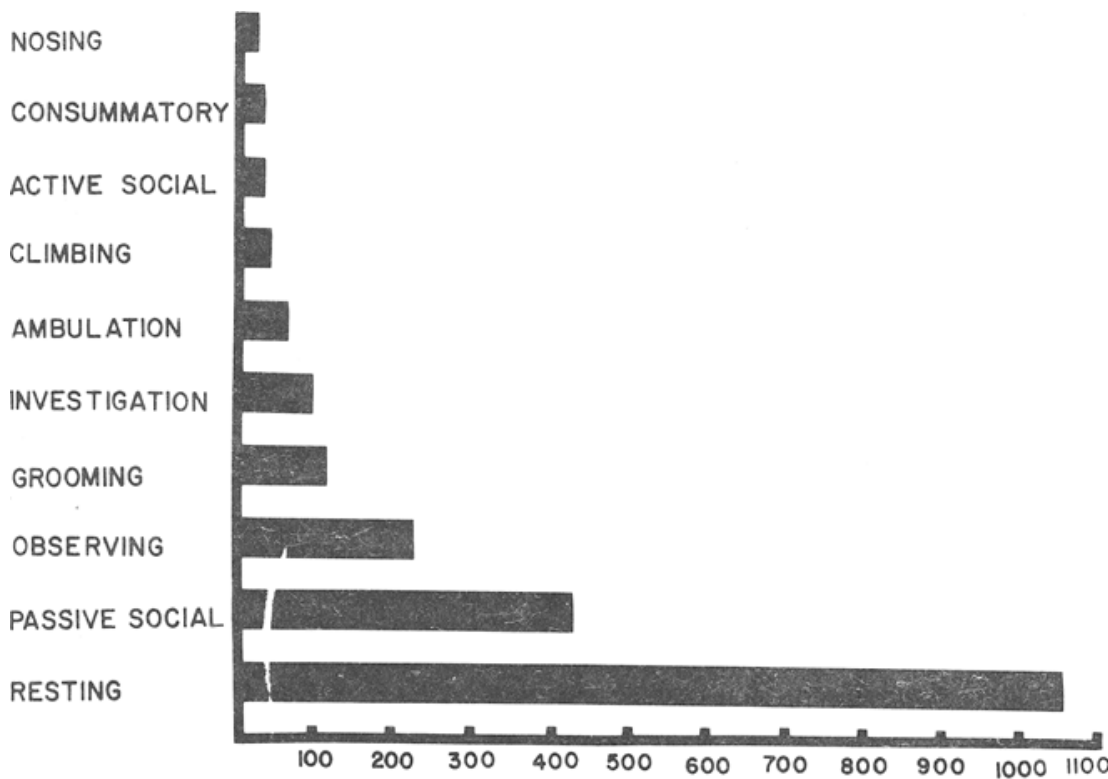

TOTAL NUMBER OF BINS

Fig. 1. Total number of bins in which the behavior was observed for the six Ss plotted against time of day. Each point represents $\mathbf{2 h}$ of observations, and is the sum of occupied bins for the even and the preceding odd hour of the day. The observed probability may be read by looking at the right side of each graph.

longer activity period, approximately $14 \mathrm{~h}$. This indicates that the animals awoke and groomed for several hours before beginning their normal nightly activities. Graph I, resting, shows a pattem which, as would be expected, is almost the inverse of Graphs G and $H$, indicating that the $S s$ spent the rest of the day resting or sleeping. Graph J, passive social, demonstrates no marked diel activity pattern.

The three groups of animals, adult males, adult females, and juvenile females, did not differ in the observed frequency of any behavior except passive social. The adult females showed a consistently higher amount of passive social contact than either of the other two groups by a factor of at least two. In every case, where these adult females displayed passive social behavior, they were in contact with another mature female.

Figure 2 shows the relative amounts of time that the opossums spent in the various behavior categories. It is obvious that these animals spent little time in vigorous activity, compared to the time they spent resting, under these conditions of captivity and possible crowding.

The results of this study may be summarized by the following daily schedule (EDT) for opossums in captivity in August in East Lansing, Michigan:

6:00 p.m.-10:00 p.m.: Awake, grooming, and sitting around.

10:00 p.m.-8:00 a.m.: Peak period of activity.

8:00 a.m.-6:00 p.m.: Resting.

\section{REFERENCES}

HARTMAN, C. G. Possums Austin: University of Texas Press, 1952.

KEEFE, J. F. The world of the opossum. Philadelphia: Lippincott, 1967.

REYNOLDS, H. C. The opossum. Scientific American, 1953, 188, 88-94.

$$
\text { NOTE }
$$

1. Thanks are given to Miss Mary Anne McNamara and Mr. Edwin Bessler for their assistance as second Os in this study, to Mr. Paul Herron for technical assistance, and to Dr. Rollin M. Baker for helpful criticism. This study was supported by NIH Grants NB 05982, 1 T01 GM 01751, 1P06-FR00366, and 1 HD-K3-11655.

Fig. 2. The total number of bins in which the particular behavior was observed for the six animals in the 24 observation periods. 